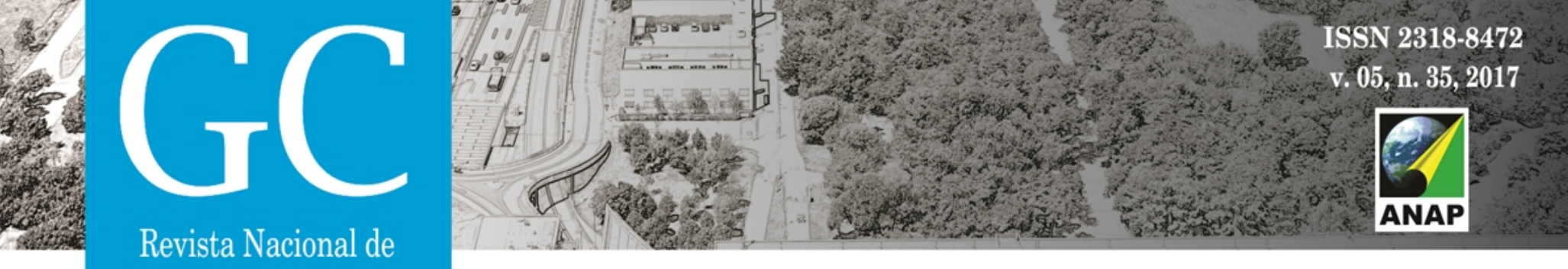

Gerenciamento de Cidades

National Journal of Cities Management

\title{
Plano de gestão de recursos hídricos em unidades de saúde
}

Water management plan for health units

plan de gestión de recursos hídricos en unidades de salud

Luciane Cleonice Durante

Professora Doutora Orientadora, UFMT, Brasil. luciane.durante@hotmail.com

Wesley de Oliveira Stiz

Pesquisador de graduação, UFMT, Brasil. wesleystiz.ws@gmail.com

José Vinnicius Ranieri Moreira

Pesquisador de graduação, UFMT, Brasil. jvinnicius@gmail.com 











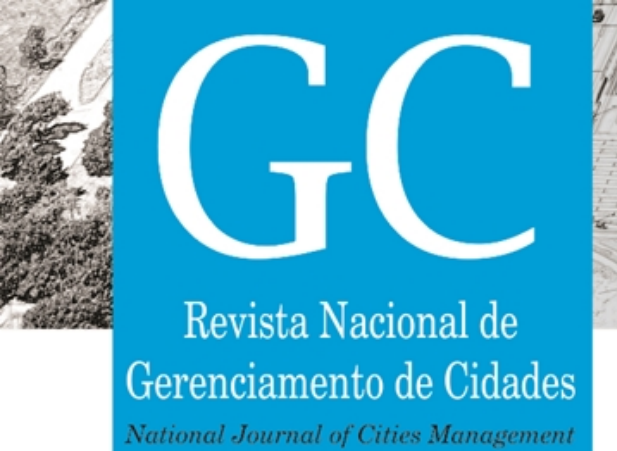

expressivo no que se refere à redução de consumo. Não se pretende com essa análise, diminuir a importância da adoção de ações educativas e de novos métodos, que são de extrema importância para potencializar o desempenho de etapas de longo prazo, tornando-se então imprescindíveis.

Observado o eixo das ações de controle de desperdício, atividade intimamente ligada ao monitoramento, tem-se que sua implementação demanda baixo investimento, muitas vezes vinculados às ações socioeducativas, mas demonstram alta performance de redução do consumo, e trata-se de uma atividade a longo prazo pois demanda atenção e manutenção constante e contínua.

A partir da redução do desperdício e desenvolvimento da educação e percepção do uso da água pelos usuários, que por si só já reduz gastos operacionais expressivamente, deve-se pensar aquisição de novos equipamentos e nas políticas de reuso, pois o próprio valor economizado naquelas ações possibilitam a aquisição destes equipamentos.

Portanto, o primeiro passo é entender a realidade das atividades e processos realizados nas unidades de saúde, particularmente. Em seguida, priorizar as etapas definidas como prioritárias. A aceitação do usuário nas mudanças deve ser encarada como uma diretriz importante do plano, pois a modernização dos equipamentos sem a compreensão e participação do usuário torna-se obsoleta, assim como uma política de reuso e reciclagem sem combater o desperdício é inviável. Por isso, a importância das ações socioeducativas que integram o usuário ao planejamento. 

BRASIL, Ministério da Saúde. Manual de Lavanderia Hospitalar. Brasília, 1986.

BRASIL. Ministério do Meio Ambiente. Agência Ambiental da Administração Pública. Comissão Gestora da A3P, Brasília, 2005. 107p - 3a ed.

BRASIL. PEC 241. Câmara de Deputados, 2016. Disponível em: < http://www.camara.gov.br/proposicoesWeb/fichadetramitacao?idProposicao=2090769 > . Acesso em 05/10/2017.

CBIC - Câmara Brasileira da Indústria da Construção. Desenvolvimento com sustentabilidade. 2014.

GREENPEACE. Desmatamento: a falta de água começa aqui. 2015. Disponível em : < http://www.greenpeace.org/brasil/pt/Noticias/Desmatamento-A-falta-de-agua-comeca-aqui/ > Acesso em 05/10/2017.

HOSPITAL DAS CLÍNICAS UNICAMP. HC estabelece plano de ações para uso racional de água. 2015. Disponível em: < https://www.hc.unicamp.br/node/898 >. Acesso em: 20/09/2017.

HOSPITAL SÃO PAULO. Procedimento Operacional Padrão: Banho no leito. São Paulo, 2013.

LIMA, Liwana Chiu de. Uso doméstico da água em hospitais: estudo de caso do hospital das clinicas da UNICAMP. Campinas, SP: [s.n.], 2007.

ILHA, M. NUNES, S. SALERMO, L. Programa de conservação de água em hospitais: estudo de caso do Hospital das Clínicas da Universidade Estadual de Campinas. Unicamp - 2006.

SAÚDE SEM DANO. Agenda Global Hospitais Verdes e Saudáveis. Disponível em < http://greenhospitals.net/wpcontent/uploads/2012/03/GGHHA-Portugese.pdf >. Acesso em 05/10/2017.

SILVA, Wilson L. A sustentabilidade no reuso da água da lavanderia do Hospital das Clínicas da UFPR. Dissertação de pós-graduação, UFPR, Curitiba 2011.

THE WASHINGTON POST. We would need 1.7 Earths to make our consumption sustainable. Disponível em: < https://www.washingtonpost.com/graphics/world/ecologicalfootprint/?utm_term=.062ef277c2ab >. Acesso em $14 / 08 / 2017$.

TNEP, The Natural Edge Project. Smith, M., Hargroves, K., Desha, C. and Stasinopoulos, P. (2009) Water Transformed - Australia: Sustainable Water Solutions for Climate Change Adaptation, Australia. Module B. Chapter 4. Lecture 4.2: The Health Sector - Water Saving in hospitals. Disponível em: <http://www.naturaledgeproject.net/Sustainable_Water_Solutions_Portfolio.aspx.> . Acesso em 18/08/2017.

VILAÇA, Vilma; OLIVEIRA, Monica. Sustentabilidade e Comunicação no contexto hospitalar: estabelecendo a necessária conscientização. Disponível em:<www.nascecme.com.br/artigos/GT2 10Pereira.pdf>. Acesso em: 09-082017. 